is quite right in pointing out that each of them gives a different emphasis to the objectives of policy--the British Government, for example, is most of all concerned to win some cash return from science and technology. The two governments have in common, however, the need to grapple with exceedingly complicated problems. Science policy runs into educational policy at one end of the spectrum and into taxation policy at the other. In circumstances like these, broad generalizations are unlikely to be convincing. Thus the way in which the OECD report rightly points to the cramping influence of specialization at British secondary schools will bring comfort to some of those who are engaged in battles to see things changed, but a report like this must necessarily seem somewhat remote and even oracular. Much the same is true of the chief recommendation of change in the administration of science in Britain-the claim that there should be a closer link between the empires maintained respectively by the Department of Education and Science and by the Ministry of Technology. A few years from now there may be a strong case for an amalgamation of these interests, but in spite of the enthusiasm of the House of Lords for this cause two weeks ago, it would be wrong to reunite science and technology under the Ministry of Technology until that recent creation knows much more clearly than at present what kinds of policies to pursue. Indeed, if the Ministry should accept the logic of its recent discovery that Keynes has as much to say as Rutherford about the translation of technology into money, it may grow to be more closely connected with the Department of Economic Affairs than with the Department of Education and Science. Then nobody knows what function the Central Advisory Council on Science and Technology will be able to work out for itself. Will Sir Solly Zucker man be a co-ordinator or simply a harassed referee? These are fascinating questions, but they cannot unfortunately be answered by appealing to what may be described as recorded science policy. In this sense OECD has probably learned as much from its examinations as have the two countries most concerned.

\section{DOES CHINA EXIST?}

FEw people are well placed to know what is happening in mainland China, and one result is that even quite simple travellers' tales are eagerly sought after by those who have been compelled to stay at home. The article by Dr K. Mendelssohn on page 10 is more than a mere anecdote, of course, but it also serves to add another morsel of flesh to the crude skeleton which must at present serve as an appreciation by outsiders of the present condition of science in China. No doubt the Chinese themselves would be alarmed to know how strangely many of their recent policies have seemed from overseas. On the face of things, for example, it is hard to reconcile the policy centred on the communes in the early sixties with the character of technology as it is known in the West. By the same test, it is not easy to see how the interests of working scientists in China will have been affected by the social phenomenon called the Cultural Revolution. Will they now be better placed to work effectively ? Or will they find that too much energy must be spent in the pursuit of orthodoxy? These are important questions, for it is only a matter of time, though perhaps a long time, before Chinese scientists are fully integrated within the international community. It is disappointing that these questions are so hard to answer.

Who is to blame? The most obvious thing to say is that there is no obvious reason why the mainland Chinese should at this stage pay close attention to the international interests of their scientists. They have other fish to fry. Yet there is plenty of evidence in the past few years of a wish somehow to demonstrate that science and technology are flourishing in mainland China. There was, for example, quite open boasting a year ago about the way in which a group of Chinese chemists had been able to synthesize insulin, and, in retrospect, there was plainly plenty to boast about. Although the synthesis of insulin was completed almost at the same time in the United States, it looks as if the Chinese group had to contend with more serious difficulties; a good many of the natural intermediates in the synthesis of insulin were not easily obtainable, for example. It is also understandable that the government at Peking should be eager to point out the cleverness with which technical people have been able to make thermonuclear weapons a mere decade after what seemed at the time to be a great step forward in nuclear technology-the opening of a modest research reactor in 1958 . Yet the scientific literature which is now increasingly available, often in translation, shows that these events are not strictly occasions for surprise. There is plenty of talent in the universities and institutes, though there is a long way to go before the research is being carried out on a scale which matches the size of China and the energy of its population.

In circumstances like these, patience is evidently the greatest need. It is too soon to expect that Chinese seientists should mix more willingly with the rest of the world. There is, however, good reason why they should be less suspicious of a continuing relationship with institutions elsewhere. After all, the Chinese themselves must know how much they gained in the fifties from their ability to move comparatively easily to institutes like that at Dubna in the Soviet Union. By now they should also have discovered that even in Western Europe, scientists do not always have horns growing out of their heads. Such exchange agreements as there have been, however, have so far been discouraging. Chinese visitors to laboratories in Europe have kept themselves in isolation. Visitors to Peking have sometimes found themselves kicking their heels in hotels. Language is an obvious difficulty, but only half the story. Is it too much to hope that exchange agreements will function more generously now that the first thermonuclear weapon has been exploded ? That would be a curious irony. 